\title{
Justicia conciliatoria durante el liberalismo hispano en el Perú: el caso de Huamanga/
}

\section{Conciliatory Justice during Hispanic Liberalism in Peru: The Case of Huamanga}

Nuria Sala i Vila

Universidad de Girona

La Constitución de 1812 estableció la división de poderes, excepto en el ámbito local. Los alcaldes tenían competencias en el gobierno interior de los pueblos y, al mismo tiempo, eran los jueces legos en las conciliaciones, un trámite preceptivo para los litigantes y para dirimir cualquier conflicto ante la justicia letrada - jueces de partido o audiencias. A partir del estudio de caso de Huamanga, se analizan los actores y la tipología de las causas dirimidas durante las dos etapas en que el virreinato del Perú ensayó la política liberal hispana -1812-1814 y 1820-1824. La cultura jurídica municipal estuvo dominada por una serie de cambios y reivindicaciones, que aportan nuevas perspectivas para comprender los convulsos tiempos de las guerras por la independencia en los Andes y que en ocasiones trascendieron a la temprana república.

Palabras Clave: Justicia conciliatoria; Cultura jurídica; Constitución de 1812; Liberalismo; Huamanga; Ayacucho; Perú, Bolivia.

The 1812 Constitution established the division of powers, except at local level. Mayors held powers in the internal government of towns and villages and were lay judges in settlements, an obligatory procedure for litigants and for resolving any dispute before the legal courts - district or provincial judges. Based on the case study of Huamanga, the players and the type of causes settled during the two stages in which the vice-royalty of Peru practised Spanish liberal politics -1812-1814 and 1820-1824- are analysed. The municipal judicial culture was dominated by a series of changes and demands, which provide new perspectives towards an understanding of the convulsed times of the wars of independence of the Andes that sometimes extended to the early republic.

Keywords: Conciliatory Justice; Judicial Culture; 1812 Constitution; Liberalism; Huamanga; Ayacucho; Peru; Bolivia. 


\section{Justicia conciliatoria durante el liberalismo hispano en el Perú: el caso de Huamanga}

La Constitución de 1812 otorgaría a todo español el derecho de dirimir sus diferencias a través de un arbitraje. El acto de conciliación y su resolución se situaba entre las competencias de los alcaldes. ${ }^{2}$ En la práctica se extendía a todo el ordenamiento jurídico una práctica habitual en los códigos de comercio y minería. Nuestro propósito es analizar el alcance de la justicia conciliatoria en el Perú, donde estuvo vigente en las dos etapas liberales hispanas, 1812-1814 y 1820-1824, a partir de un estudio de caso, la ciudad de Huamanga, rebautizada Ayacucho tras la Independencia. Como colofón intentaremos apuntar la influencia que tal proceso tuvo en el ordenamiento jurídico de las tempranas repúblicas peruana y boliviana. Nuestro análisis se sustenta en los dos libros de actas de las causas vistas en justicia conciliatoria por los alcaldes de primera y segunda nominación de Huamanga ${ }^{3}$ y la generada por la administración judicial de la audiencia nacional del Cusco.

La transición de una cultura jurídica ilustrada a la liberal y su incidencia en el proceso de construcción del Estado republicano que surgió de la independencia ha sido objeto de atención por autores como Carlos Ramos o Víctor Peralta. ${ }^{4} \mathrm{Si}$ bien se ha avanzado en el conocimiento de las primeras corporaciones locales electivas, ${ }^{5}$ ante la persistencia de la justicia lega y la concentración de los poderes gubernativo y judicial en manos de los alcaldes durante el liberalismo hispano y el constitucionalismo peruano, sigue pendiente de análisis la coexistencia, tensión o lenta sustitución de la justicia lega por la letrada en la transición del mundo colonial de Antiguo Régimen a la temprana República. ${ }^{6}$

1 Investigación financiada por el Ministerio de Ciencia e Innovación, HAR2011-23225/HIST.

2 Constitución de 1812, Capítulo II de la administración de justicia en lo civil, arts. 280-284.

3 Archivo Regional de Ayacucho (en adelante ARAy), Libros Cabildo, leg. 17, Libro de Determinaciones de conciliación. Alcaldía de 1. ${ }^{a}$ nominación (en adelante LC, 17, LDC1), 1813-28, 167 fs. y Libro de determinaciones de conciliación de la alcaldía de 2. ${ }^{a}$ nominación (en adelante LDC2), 1813-1828, 134 fs.

4 Ramos, 2003, I y IV; Peralta, 2010.

5 Chiaramonti, 2007; Paniagua, 2003; Gamio, 1944; Peralta, 2010, siguen siendo los estudios fundamentales, aunque en general se centran en el Primer Liberalismo y analizan muy tangencialmente el Trienio Liberal.

6 Para regiones, como México o Ecuador, en que como en el Perú, influyó de una u otra forma el liberalismo hispano, véase Annino, 2010; Morelli, 2008. Para Argentina: Fradkin (comp.), 2007; Barriera, 2010. En general han dominado los estudios sobre los cambios inducidos en el gobierno local o en las comunidades indígenas: Ortiz y Serrano (eds.), 2007; Salinas, Birrichaga, Escobar (coords.), 2011; Guarisco, 2003. 
Huamanga con cerca de diez mil habitantes era una ciudad administrativa — sede de intendencia y obispado-, residencia de artesanos —panaderos, tejedores—, comerciantes — muchos de ellos mestizos, especializados en la trata de ganado, productos de pan llevar o textiles- y propietarios absentistas o arrendatarios de fundos agrícolas y ganaderos dispersos en la diversidad de pisos ecológicos regionales, que producían trigo, alfalfa, maíz, carnes y cueros en las zonas altas, o azúcar y coca en los cálidos valles interandinos del Pampas o en la selva alta de Anco y Huanta. ${ }^{7} \mathrm{La}$ Universidad de San Cristóbal, aunque no viviera sus mejores momentos, le daba carácter, y quizás por ello clérigos, frailes y profesores tenían un papel social y cultural destacado. Los conventos de San Francisco, Santo Domingo, San Juan de Dios, La Merced, Santa Clara o el Carmelo de Santa Teresa no solo dominaban la trama urbana e imponían fuerza a una religiosidad aún impregnada del espíritu barroco tridentino, sino que actuaban de agentes del crédito urbano y agrario. ${ }^{8}$ En la práctica la coyuntura bélica originó una compleja, persistente e intermitente distorsión de las producciones agrarias rurales y de los circuitos comerciales huamanguinos, tanto los que vinculaban la zona con la costa, como los que a través de Huanta o Cangallo lo hacían con la sierra central —Pasco, Jauja o Tarma-, o con el Pampas y las zonas altas ganaderas del sur.

Las dos etapas dominadas por los presupuestos liberales hispanos introdujeron transformaciones legales y gubernativas sustanciales, sobre todo en lo relativo al gobierno local, cuando el cabildo y los regidores perpetuos de Huamanga fueron sustituidos por un ayuntamiento electivo, mientras que villas y pueblos pudieron autogobernarse por primera vez tras constituir sus respectivos ayuntamientos. Al mismo tiempo la ciudad y región se verían condicionadas por una fuerte conflictividad regional, en una suerte de dicotomía guerra-revolución. El primer liberalismo culminaría con los ecos de la insurgencia cuzqueña de 1814, cuando la columna dirigida por Hurtado de Mendoza tomó la ciudad y Huanta. Durante el segundo liberalismo, entre 1820 y 1824 , la situación política regional estuvo condicionada por las campañas militares y la insurgencia interna: la invasión del ejercito patriota del general San Martín, a partir del 20 de septiembre de 1820, supuso la ruptura de las comunicaciones y circuitos comerciales con la costa; durante la campaña del general José Álvarez de

7 González, Gutiérrez, y Urrutia, 1995, 91 y 92.

8 Peralta, 2001. 
Arenales desde el 31 de octubre de 1820 la ciudad fue ocupada durante un breve periodo, ocurriendo lo mismo en Huanta, Jauja y Tarma; la represión realista fue contundente, al punto que Mariano Ricafort se ensañó con los montoneros morochucos, incendió Cangallo el 2 de diciembre de 1820 y reconquistó Huamanga; José Carratalá ordenó incendiar de nuevo Cangallo el 17 de diciembre de 1821; las represalias continuaron en 1822 ante la persistencia de acciones patriotas, siendo ejecutados María Parado de Bellido, Basilio Auqui o el morochuco Cayetano Quiroz en Ica. ${ }^{9}$ Sin embargo, la ciudad de Huamanga, excepto el interregno de la ocupación patriota de fines de 1820, siguió bajo control realista hasta agosto de 1824, ocurriendo en general lo mismo con la región hasta la batalla de la Pampa de la Quinua el 9 de diciembre de 1824 y la capitulación del ejército español.

\section{La justicia municipal en el temprano liberalismo hispano}

La convocatoria a Cortes, los sucesivos debates de los diputados en Cádiz y la promulgación de la Constitución de 1812 evidenciaron pronto que el proceso abierto con la invasión francesa de la Península desembocaba en la liquidación del Antiguo Régimen y en la construcción de un nuevo entramado político, basado en la división de poderes, con cambios sustanciales en la administración gubernativa y judicial. Se reconocía un único fuero y, en consecuencia, sólo se contemplaba desarrollar un único código civil, criminal y de comercio para el conjunto de la Monarquía, con la salvedad de conservar la vigencia de los fueros eclesiástico y militar. El sistema judicial se estructuraba piramidalmente: un Supremo Tribunal de Justicia con sede en la Corte, Audiencias, Jueces de Letras en los partidos, y alcaldes en los pueblos. Se posponía a una legislación posterior la determinación del número y la jurisdicción territorial de las Audiencias, divididas interna y proporcionalmente en diversos partidos judiciales. Con carácter provisional y hasta cuando las Cortes lo considerarán conveniente o legislarán sobre el particular, se mantuvo la salvedad de ciertos juzgados privativos, como fueron los de Hacienda Pública, Consulados y Tribunales de Minería con competencias en temas fiscales, comerciales y minería. ${ }^{10}$

9 Igue, 2008.

10 Constitución de 1812, art. 11. Título V, De los Tribunales y de la administración de justicia en lo civil y en lo criminal. Cap. I, De los Tribunales, arts. 248, 249, 250, 258, 259, 262, 272, 273 y 275 y Cap. II, art. XXXII. 
La organización y competencias jurídicas se desarrollarían en el Reglamento de las Audiencias y Juzgados de primera instancia de 9 de octubre de 1812. En Ultramar, los jefes políticos superiores y de provincia - antiguos virreyes e intendentes del ordenamiento absolutista - perdieron toda competencia en justicia, excepto el fuero militar; se suprimieron los cargos de asesores letrados; se prohibió la intervención de las audiencias y jueces de letras en asuntos gubernativos o económicos y se ordenó a las primeras la transferencia de los asuntos en trámite a las diputaciones provinciales y se optó por suprimir las subdelegaciones desde el momento en que las diputaciones provinciales, de acuerdo con la audiencia preceptiva, hubieran fijado los nuevos distritos judiciales y nombrado los respectivos jueces de letras, atendiendo a principios de proporcionalidad territorial y al número de vecinos. ${ }^{11}$ Sabemos poco de la concreción real de tales disposiciones y sólo tenemos constancia del proyecto redactado por la diputación provincial limeña en 1814, un proceso que quedó trunco tras el retorno al absolutismo. ${ }^{12}$ Ante la dificultad por consensuar la división provincial prevista en la Constitución de 1812, se reconocieron provisionalmente las audiencias de Lima, Cusco y Charcas ${ }^{13}$ adscribiéndoles el mismo territorio jurisdiccional vigente hasta entonces y manteniendo la misma sede. ${ }^{14} \mathrm{La}$ ocupación de Lima por San Martín determinó de facto la desaparición de la audiencia de Lima. Esta situación fue resuelta por el virrey José de La Serna con la reordenación del mapa judicial peruano a partir de las audiencias nacionales subsistentes, Cusco y Charcas. ${ }^{15}$ Se le asignó el carácter de audiencia territorial a la primera, siéndole adscritas las provincias de Tarma, Huancavelica, Huamanga y Arequipa, antes dependientes de la de Lima, ${ }^{16}$

11 Reglamento de las Audiencias y Juzgados de primera instancia de 9 de octubre de 1812, Lima, Imprenta de los Huérfanos por don Bernardino Ruiz, 1813. Cap. I, De las Audiencias, art. XIV y Cap. II, arts. LXIV, VIII, XXX y XXXI y Cap. II, De los Jueces letrados de partido, art. I, III, IV, V y VI. En Ultramar debía procurarse que tuvieran juez letrado los territorios de más de 5.000 vecinos y en aquellos partidos preexistentes, que no pudieran agregarse a otros por su localidad, distancia o extensión

12 Los informes han sido publicados en Castillo, Figallo y Serrera, 1994, 397-504.

13 Charcas volvió a la administración del Perú, tras independencia de facto del Río de La Plata.

14 Reglamento de 9 de octubre de 1812, Cap. I, De las Audiencias, art. I.

15 Archivo Regional del Cusco (en adelante ARC), Cedulas Reales, leg. 3, 1820, Jorge García de la Torre al Regente, Madrid 14.3.1820, con anotación de haberse recibido en Cusco el 21.10.1820, si bien se estaba cumpliendo desde 15.10.1820.

16 ARC, Intendencia, Gobierno, Pedimentos, Leg. 242, 1814-24. Expediente sobre que quedan agregadas al territorio de esta Audiencia Nacional las Provincias de Tarma, Guancavelica, Guamanga y Arequipa mientras la ocupación de Lima por los disidentes, 8.1.1822. José de la Serna a la Audiencia Nacional de esta Capital, Cuzco, 5.1.1822. 
y a partir de mayo de 1823 la de Chiloé, ${ }^{17}$ con la finalidad de asegurar el derecho de apelación, la provisión de vacantes de jueces y dirimir las dudas de interpretación constitucionales. ${ }^{18}$

En lo local, se legisló que «en todos los pueblos se establecerán alcaldes, y las leyes determinarán la extensión de sus facultades, así en lo contencioso como en lo económico». ${ }^{19}$ Ello significaba que se atribuía a los alcaldes electos el oficio de conciliadores, con competencias en causas civiles o de injurias. Debían escuchar los argumentos de las partes enfrentadas y de sus hombres buenos, cuya intervención buscaba reforzar sus alegatos legales, ${ }^{20}$ y emitir una providencia en el plazo de ocho días, que podía o no ser aceptada por las partes. Todo el proceso debía quedar testimoniado en un libro de actas, anotarse los datos de las partes en litigio y las causas de sus discordias, describir las actuaciones o la documentación aportada, sus alegaciones y descargos, los dictámenes de los hombres buenos, aunque en Huamanga en la práctica sólo se anotaron con fecha y firma cuando había disenso. Se concluía con la providencia de conciliación, fundamentada por el alcalde, y al pie las rúbricas de éste, de los hombres buenos y de las partes en litigio, o de un representante legal si alguno no supiera firmar. Debía dejarse constancia cuando alguna de las partes no se avenía a la provisión conciliatoria, para emitir una certificación, trámite imprescindible para entablar posteriores apelaciones a instancias judiciales letradas. ${ }^{21}$

Los alcaldes podían actuar además, y siempre según el Reglamento, en las diligencias judiciales relativas a asuntos civiles, hasta que llegaran a ser contenciosas entre las partes, momento en que debían elevarlas al juez

17 ARC, Corte Superior de Justicia, Archivo Administrativo, Libro 36, Libro 1 del despacho diario de la Audiencia Constitucional del Cuzco en su primera Sala, Expediente sobre entablar constitucionalmente en la provincia de Chiloé la administración judicial civil y criminal, 1.5.1823.

18 ARC, Intendencia, Gobierno, Pedimentos, leg. 242, 1814-24. Acuerdo de 7.2.1822, Regente, Corbalán, Darcourt y fiscal con presencia del virrey.

19 Reglamento de 9 de octubre de 1812, Título V De los Tribunales y de la administración de justicia en lo civil y en los criminal y en el Capítulo I De los Tribunales, art. 275,

20 Ibidem, Cap. II De la administración de justicia en lo civil, arts. 280-4 y Cap. III De los Alcaldes constitucionales de los pueblos.

21 Ibidem, Cap. III, art. I y II, Cap. IV De la administración de justicia en primera instancia hasta que se formen los partidos, art. VI. En general, la Audiencia del Cusco exigió a los alcaldes que emitieran preceptivamente la providencia de conciliación, en tal sentido ARC, Real Audiencia, Administrativo, leg. 179, Auto de la Audiencia firmado por el regente, Darcourt y Zavala aviniéndose al dictamen del fiscal Mugica de 8.1.1823 en la Representación del Juez de Letras sobre el abuso de los alcaldes conciliadores en no terminar resolutivamente algunos negocios de que conocen en los juicios conciliatorios. 
del partido, aunque podían también hacerlo de forma inmediata en aquellos casos de urgencia en que no fuera posible recurrir al juez de letras. ${ }^{22}$ Podían proceder de oficio, hubiera o no un juez de letras residente, para reprimir algún delito o delincuente, iniciar las primeras formalidades de la sumaria y detener a reos descubiertos in fraganti o cuando por ley las penas pudieran ser corporales, si bien debían trasladar los reos y diligencias al juez; al mismo tiempo un juez letrado, que necesitara actuar a través de partes o delegados, sólo podía recurrir al alcalde. En Ultramar, se otorgaba a los alcaldes competencias en las causas civiles con demandas no superiores a los cien pesos fuertes y en las causas criminales sobre injurias y faltas livianas que no requirieran más que reprensión o una ligera corrección. Ambos supuestos debían ser vistos y sentenciados en juicio verbal, oyéndose los pareceres de hombres buenos electos por las partes, sin que la sentencia fuera apelable y con la obligación de su registro pormenorizado en un libro de actas, firmando al pie de cada apunte el alcalde, los hombres buenos y el escribano. ${ }^{23}$ En el Perú se les asignó, a partir de 1821, en pueblos carentes de escribanos públicos, todo lo relativo a últimas voluntades y testamentos $^{24} \mathrm{y}$, a partir de 1822, también los pleitos mercantiles cuando no fuera posible la actuación de los respectivos diputados de comercio provinciales y con el objetivo de llenar el vacío generado por la inactividad del Tribunal del Consulado tras la ocupación de Lima. ${ }^{25}$ A la par, aunque sólo tenemos constancia documental para Cusco y Puno, se les negó cualquier competencia contenciosa fuera de sus respectivas ciudades, limitando la jurisdicción de los alcaldes de las capitales provinciales a la propia urbe. ${ }^{26}$ Hasta que no se hubieran constituido los respectivos ayuntamientos, al menos en el Perú, los jueces de letras mantendrían de forma interina las competencias gubernativas y de justicia conciliatoria en el ámbito local. ${ }^{27}$

22 Ibidem, Cap. III, art. VI y VII.

23 Ibidem, Cap. III, art. V, VIII, IX y X.

24 ARC, Intendencia, Gobierno, Pedimentos, leg. 242, 1814-24, Acuerdo de la audiencia del Cusco, 16.11.1821, firmado por el regente, Corbalán, Darcourt y Mosquera. Sólo en los casos en que hubiera contradicción los alcaldes debían elevar el caso al subdelegado, debiendo actuar siempre con dictamen de letrado.

25 Archivo General de Indias (en adelante A.G.I.), Lima, 762, Carta de La Serna al Secretario de Estado y del Despacho de Hacienda, 29.9.1822, adjuntado su decreto de 20.9.1822.

26 ARC, Corte Superior de Justicia, Archivo Administrativo, Libro 36, Libro 1 del despacho diario de la audiencia constitucional del Cuzco en su primera Sala, vista del expediente en 18.10 y acuerdo en 24.10.1821.

27 ARC, Cédulas Reales, leg. 3, De Jorge García de la Torre al Regente, Madrid, 14.3.1820, orden al margen de comuníquese dada en Cusco a 27.9.1820. 
En consecuencia, el temprano liberalismo hispano establecía, como ha señalado Federica Morelli, una naturaleza de la justicia de base dual: «podría ser letrada y ajena a las corporaciones municipales, o lega, electiva, y, por tanto, vinculada a éstas», con una cierta tensión entre la pervivencia del derecho antiguo y los presupuestos liberales. ${ }^{28}$ Desde la historia del derecho constitucional, Luis Morell interpreta que el Decreto CCLXIX de 23 de junio de 1813, Instrucción para el gobierno económico-político de las Provincias, atribuía al ayuntamiento, presidido por el alcalde, el gobierno interior de los pueblos; pero que ante todo se confería al alcalde atribuciones de juez, y por ello se le citó, en la legislación constitucional gaditana, dentro de los temas de justicia, lo que en el fondo presuponía la persistencia de las competencias que habían asumido en el Antiguo Régimen. ${ }^{29}$ Nos interesa destacar el hecho de que la concentración de poderes situó a los alcaldes en una doble posición de dependencia de los poderes gubernativo y judicial. Así la audiencia nacional de Cusco exigió que, a tenor de sus competencias judiciales, los alcaldes constitucionales prestaran juramento ante dicho tribunal para acatar el artículo 7..$^{\circ}$ del Reglamento de 9 de octubre de $1812 .{ }^{30}$ A pesar de ello y atendiendo a las distancias, se aceptó que los de Puno, Arequipa o Huamanga lo hicieran in situ, fuera de sede judicial. Su voluntad de ingerencia, y cierta tensión entre su defensa de la justicia letrada frente a la lega, determinó su recomendación al jefe político superior de la provincia de Puno, Tadeo Gárate, para que influyera en los electores en preferir como alcaldes a ciudadanos «capaces de desempeñar las funciones judiciales $»^{31}$ o para persuadir a alcaldes calificados de poco versados en procedimientos legales, como el de Arequipa en 1822, a actuar asesorados por letrados imparciales y no abusar de su autoridad, «ni de las Leyes que le estrechan obrar con justicia». ${ }^{32}$

28 Morelli, 2008, 48. Un análisis de los cambios en el Trienio Liberal en Martínez Pérez, 1999.

29 Morell, 2003, 121-146.

30 ARC, Intendencia, Gobierno, Pedimentos, leg. 242, 1814-24. Expediente de Acuerdo sobre que los SS Alcaldes constitucionales presten su respectivo Juramento en este Superior Tribunal y ante su regente Presidente de esta Audiencia Nacional, 20.11.1820. Auto firmado por el Regente, Corbalan, Darcourt, Mosquera, Cusco, 5.12.1820.

31 ARC, Real Audiencia, Administrativo, leg. 178, 1821-22. Expediente sobre que los SS Jefes Políticos de las Provincias de Puno, Arequipa, Guamanga, Guancavelica y Tarma a nombre del señor Regente Presidente de esta Exma Aud. ${ }^{a}$ recivan el Juramento prescripto en el artículo 7. ${ }^{\circ}$ del decreto de 9.10.1812 anualmente a los Alcaldes Constitucionales de sus respectivas Provincias.

32 ARC, Corte Superior de Justicia, Archivo Administrativo, Libro 36, Libro 1 del despacho diario de la audiencia constitucional del Cuzco en su primera Sala, Real Provisión emitida por la audiencia del Cusco en 2.5.1822 y librada al alcalde $1 .^{\circ}$ de Arequipa. 


\section{La justicia conciliatoria en el Ayuntamiento Constitucional de Huamanga (1813-14 y 1821-24)}

Durante el primer liberalismo hispano se dirimieron en Huamanga diecisiete conciliaciones, seis ante el alcalde de primera nominación, entre el 1 de octubre de 1813 y el 28 de febrero de 1814, y once ante el alcalde de segunda nominación, entre el 8 de mayo de 1813 al 30 de abril de 1814 . Durante el Trienio Constitucional hubo ciento una conciliaciones, cuarenta ante la alcaldía de primera nominación, entre el 19 de octubre de 1820 y el 11 de marzo de 1824, y sesenta y una ante la de segunda nominación, entre el 29 de enero de 1821 y el 27 de febrero de 1824 .

El procedimiento formal llevó a desglosar en dos libros separados las actuaciones de las dos alcaldías de Huamanga. No siempre hemos podido verificar si se cumplió el precepto legal de resolver la conciliación en el plazo de ocho días, aunque en varios casos se perciben dilaciones. Las actuaciones exigían la presencia de las partes, o en su defecto, de sus apoderados o del defensor de ausentes. Un varón familiar directo debía representar a las mujeres y menores de edad, y respecto a éstos hacerse presente el protector de menores. Los indios tuvieron dos tratos distintos, antes y después de la abolición del protector de naturales, debiéndose justificar documentalmente en el primer caso la actuación del cargo tutelar. En las páginas de los citados libros se constatan diversas caligrafías, muestra de la intervención de varios escribanos, lo que denotaba cierto nivel de institucionalidad y la disponibilidad de recursos económicos para financiar las actuaciones. En ningún caso se especifican las costas del proceso; sólo aparecen referencias tangenciales a la necesidad de nombrar peritos para tasar, inventariar o efectuar determinadas diligencias. Existen ciertas evidencias de la asignación del pago de costas a una de las partes, aunque no queda claro cuál fue el procedimiento para fijarlas. Los costos de la administración de justicia fueron una más de las nuevas competencias que gravaron sustancialmente los presupuestos de los ayuntamientos, un reto difícil de afrontar, sobre todo en los carentes de propios y arbitrios, situación que sólo podía resolver la diputación provincial. Desconocemos cómo se resolvió en Huamanga, pero en Puno su diputación provincial fijó un arancel y la audiencia del Cusco acordó que, en su jurisdicción, los alcaldes no exigieran honorarios por sus actuaciones y que los litigantes costearan 
sólo el papel sellado y una tasa de dos reales por emitir cualquier certificación. ${ }^{33}$

Reproducimos a continuación los nombres de quienes ejercieron de jueces conciliadores, los cargos para los que fueron electos y los periodos en que se registró su actuación, y cuando, accidentalmente y por excedencias temporales, los alcaldes serían substituidos por regidores.

\section{CUADRO $1 .^{\circ}$}

JUECES CONCILIADORES. PRIMER PERIODO CONSTITUCIONAL

\begin{tabular}{lcc} 
Alcaldía $1 .{ }^{a}$ nominación & & Fecha \\
\hline José Joaquín Toledo Pimentel & $\mathrm{A}$ & 1 a 26.18 .1813 \\
Palomino de Mendieta & $\mathrm{R}$ & 6 a 18.12 .1813 \\
Fernando Fernández y García & $\mathrm{A}$ & 18.1 a 28.2 .1814 \\
& & \\
Alcaldía $2 .{ }^{a}$ nominación & & Fecha \\
\hline Francisco Tincopa & $\mathrm{R}$ & 8.5 .1813 \\
Gregorio Ulloa & $\mathrm{A}$ & 6.7 a 15.12 .1813 \\
Francisco de Araujo & $\mathrm{A}$ & 21.1 a 30.4 .1814
\end{tabular}

CUADRO 2. ${ }^{\circ}$

JUECES CONCILIADORES. TRIENIO CONSTITUCIONAL

Alcaldía 1. ${ }^{a}$ nominación

Raymundo Gómez de Segura

Miguel de Yriarte

José de Gálvez

Rafael Muñoz

Vicente Ruiz

José Carrasco

Gregorio Flores

José López
Fecha

$\begin{array}{cc}\mathrm{A} & 19 \mathrm{a} 24.10 .1820 \\ \mathrm{~A} & 1821 \\ \mathrm{~A} & 15.6 \mathrm{a} 6.8 .1822 \\ & 5.11 .1822 \\ \mathrm{R} & 11.9 .1822 \\ \mathrm{R} & 25.115 .2 .1823 \\ \mathrm{~A} & 24.4 \mathrm{a} 10.12 .1823 \\ \mathrm{R} & 29.1 .1824 \\ \mathrm{~A} & 5.3 \mathrm{a} 11.3 .1824\end{array}$

33 ARC, Corte Superior de Justicia, Archivo Administrativo, Libro 36, Libro 1 del despacho diario de la Audiencia Constitucional del Cuzco en su primera Sala, Acuerdos de 16, 19.11 y 27.12.1823 y de 9.1.1823. 


\begin{tabular}{lcc} 
Alcaldia $2 .{ }^{a}$ nominación & & Fecha \\
\hline José Soto & A & 1821 \\
Raimundo Gómez Arriaran & A & 19.1 a 3.7 .1822 \\
Rafael Muñoz & R & 30.7 a 13.9 .1822 \\
& & 5.10 a 23.12 .1822 \\
Juan Trias & R & 20.9 .1822 \\
Marcos Pantoja & A & 1823 \\
José Luis de Ochoa & A & 1824 \\
\hline
\end{tabular}

A Alcalde, $\mathbf{R}$ Regidor

Aunque sabemos poco de las historias de vida de los alcaldes constitucionales, algún caso apunta a su cercanía a sectores económicos regionales y proclives a asumir posiciones liberales. Así, Miguel Iriarte y José Soto eran comerciantes o José Carrasco hacendado. Iriarte fue diputado de comercio y, como el mayor contribuyente local, aportó cinco mil pesos en el empréstito forzoso de fines de $1821 . .^{34}$

En la primera etapa liberal hubo treinta y cuatro intervenciones de hombres buenos en diecisiete conciliaciones, correspondientes a catorce personas distintas: siete actuaron en una ocasión, ${ }^{35}$ dos repitieron, dos en tres ocasiones, ${ }^{36}$ dos en cuatro -Pedro Mariano Munárriz y Juan Valdivia- y Juan José González en nueve. En la segunda etapa liberal hubo ciento veintiocho actuaciones de hombres buenos en las ciento y una conciliaciones del periodo, al multiplicarse proporcionalmente los representantes en causas que implicaban a varias partes. Se implicaron cincuenta y nueve personas: treinta y seis en una ocasión, ${ }^{37}$ ocho en dos, ${ }^{38}$ tres en

34 Sala i Vila, 2011.

35 José Vicente Egurola, Miguel de Iriarte, Esteban Morales, Juan de Dios Muñoz, José Ochoa, Felipe Santiago Revoredo, Vicente Ruiz Adán.

36 Pedro José González y Vicente León en dos; Julián Caro y Luis de Roxas en tres.

37 Francisco Aguirre, Mariano Amorín, José Miguel de Ayarza, Celedonio Barbarán, Andrés Borja, Tomás Cárdenas, Pascual Castillo, Manuel Corrales y Quintanilla, Pedro Cueto, Jerónimo Esquiros, José Falconí, Fernando Fernández García, Atanasio Francesqui, Lucas Francisco Frejo, José de Gálvez, Raymundo Gómez y Arriarán, Pedro José González, Pedro de la Hermosa, Miguel de Iriarte, Andrés Jáuregui, Mariano Jayme, José Manuel Lagos, José Francisco Lama, Jacinto López, José Martín, Esteban Morales, José Antonio Morote, José Negli, Eustaquio Pacheco, José Ribera, Francisco Rodríguez, Lorenzo Sanz de Santo Domingo, Juan Francisco Soto, Juan Tamayo, Manuel Vizcarra y Jacinto Ynfanzón.

38 Ignacio del Alcazar, José Carbajal, Lorenzo Guerrero, Oclo Ynga, José Manuel Gutiérrez, Ignacio Lucero, Pedro Mariano Munárriz, Juan de Dios Muñoz y Benito Roxas. 
tres, una en cuatro, tres en cinco, ${ }^{39}$ Calixto de Rivera en nueve, Lorenzo Palomino en once, Juan García de los Godos en dieciséis, Luis de Roxas en diecisiete, Luciano María Cano en veintiuna, Julián Caro en veintidós y, por último, Cayetano Medina y Urquizu en veintiocho. Todo apunta a cierta tendencia a la profesionalización de la figura del hombre bueno o cuanto menos a que el alcalde, ante cierta falta de decisión propia de las partes implicadas, resolviera cubrir el imperativo de nombrar un hombre bueno recurriendo a funcionarios municipales, gente de confianza u hombres de derecho, sobre todo en casos de especial complejidad legal. Si bien desconocemos el número de abogados existentes en la Huamanga del temprano siglo XIX, cabe pensar que eran pocos, lejos de la presencia significativa de tales profesionales en ciudades sedes de audiencias como Lima, Cusco o Charcas. Los ejemplos de lo expuesto se hallarían en la reiterada intervención de Julián Caro, oficial mayor de la secretaría del ayuntamiento, o de Ignacio Alcazar, contador de la Caja Nacional, y de Luciano María Cano y Bernardino Estébanez de Ceballos, abogados respectivamente de las audiencias de Lima y Lima y Cusco o de Vicente León, abogado de los tribunales de la nación y de la audiencia constitucional de Lima, regidor y secretario del ayuntamiento de Huamanga. A pesar de que, en general, sólo se incluyera en el acta el nombre y apellidos, su profesión, cargo o título académico, pueden singularizarse regidores —José Vicente Egurrola, Jacinto López, Juan de Dios Muñoz- o comerciantes como Miguel de Iriarte (alcalde en 1821). Algunos detentaron varios puestos, como Cayetano Medina y Urquizu, que ejerció de síndico procurador del Monasterio de Santa Teresa o de defensor de ausentes. En varios se constata su condición de aforados, por ser oficiales de milicias (capitanes José Carbajal, Juan José y Pedro José González en las de Huamanga, tenientes Juan de Dios Muñoz y José Ochoa o subtenientes Juan Valdivia y Jerónimo Esquiros en las de Huanta) o bien presbíteros (Juan García de los Godos, Andrés Jáuregui, Pedro Mariano Munárriz) o regulares (fray Manuel Corrales y Quintanilla, lector de moral, y fray Francisco de Aguirre, ambos mercedarios). Su participación fue consecuencia de un debate de las Cortes de 1821 , en el que se concluyó que el acto de conciliación no podía ser considerado como un juicio, lo que permitió tanto la participación de aforados, como la obligatoriedad de dirimir en primera instancia toda causa que les

39 En tres ocasiones: José Lira, Justo Prado y Bernardino Sáez; en cuatro: José Santiago Carrasco y Bernardino Estevanez de Ceballos; en cinco: José Matías León, Juan Valdivia y Miguel de Villavicencio. 
afectara en conciliación. ${ }^{40}$ Quizás por ello las conciliaciones afectaron a un número creciente de aforados: dos de 1813 a 1814 y veintitrés de 1820 a 1824 .

En conjunto y a pesar de que sabemos poco aún de las historias de vida regionales, ciertos indicios apuntan a que varios de los actores que intervinieron en la justicia local, como alcaldes conciliadores y hombres buenos, tuvieron una trayectoria política próxima a presupuestos liberales, con una decidida actividad pública y política en la temprana República. Sólo a título de ejemplo y como avance de investigación, señalaremos que Juan Valdivia fue diputado suplente en la convención nacional de 1833; o que Luciano María Cano, arequipeño, fue sucesivamente protector de naturales de Huamanga en 1819 y secretario de la diputación provincial de Huamanga en 1822. ${ }^{41}$ Considerado en medios locales de ideas liberales ${ }^{42}$ sería tras la Independencia asesor del gobierno del general Álvarez Arenales, presidente de la junta de beneficencia en 1826, secretario de la prefectura y juez de derecho en Ayacucho y su provincia en $1827,{ }^{43}$ vocal de la corte superior de justicia del Cusco en $1833,{ }^{44}$ senador por Ayacucho en 1833 y secretario del consejo de Estado en 1835. En consecuencia, y si bien queda pendiente trazar las historias de vida individuales y colectivas de los actores del temprano liberalismo, todo apunta a la intervención de varios de ellos en la construcción de los nuevos parámetros de la cultura jurídica y política que se tejió en los tiempos en que se resquebrajaba el Antiguo Régimen colonial y aún era incierto si el liberalismo se impondría de la mano y obra de la Constitución de 1812 o de la peruana de 1823.

\section{Tipología de las causas vistas en conciliación}

Unas pocas conciliaciones terciaron en causas de injurias - seis de las ciento y una entre 1820 y 1824 - , las cuales dejan entrever ciertas pautas de sociabilidad en las que dominaba la bronca y el exabrupto y una no desdeñable violencia física cotidiana. Acusaciones de insultos y agresiones

40 Martínez Pérez, 1999, 484-492.

41 AGNP, Superior Gobierno, 189, 1183, 31, Autos promovidos por Francisco Hernández oponiéndose al nombramiento de secretario de Luciano María Cano, 2.0.1822.

42 Biblioteca Nacional del Perú (en adelante BNP), D 6037, Cuaderno copiador de oficios y comunicaciones de carácter oficial, Huamanga, 14.1.1825. Informe a favor de Luciano María Cano.

43 ARC, Corte Superior de Justicia, Archivo Administrativo, 59 Libro copiador de la Correspondencia oficial de la Regencia, 1820-23.

44 Florez, 1834, 59. 
físicas se cruzaron entre varias mujeres, en ocasiones subyacentes a la trasgresión de las normas al uso sobre la fidelidad conyugal. Se resolvieron dando por suficiente la cárcel sufrida por una de las implicadas en peleas, multando a la agresora e imponiendo silencio a las partes; o también dando garantías de la moralidad vigente mediante el destierro de una «concubina» [sic], por su nulo arraigo, a lo cual no se avino la afectada, ${ }^{45}$ previa argumentación del hombre bueno de una de las partes, Pedro José González, de que en tales casos «no nos debemos valer de la fuerza de las Leyes, sino de la razón». ${ }^{46}$ Ello nos lleva a concluir que prevaleció el sentido común, antes que el ordenamiento legal, teñido de un fuerte espíritu moral en defensa del matrimonio cristiano.

De igual modo, en el propio proceso de conciliación no todo fue paz y orden o estuvo presidido por las buenas maneras. Ello se demostró en el litigio por la posesión de la hacienda Ostuna de la testamentaría del cura de Hualla, Manuel Hernández, dirimido entre el abogado Bernardino Estébanez de Ceballos, esposo y representante legal de la sobrina del finado, Catalina Hernández, y el hermano del mismo, Francisco Hernández, cuando ambos se enardecieron «en expresiones que pasaban a personalidades de un modo que se tocó con una dificultad insuperable para que puedan tratar en acto de conciliatorio». ${ }^{47}$ En 1822, en otro episodio, Hernández, que había sido regidor del ayuntamiento, cuestionó a Estébanez como elector del partido de Anco. ${ }^{48}$

Si bien ciertos casos se enraizaban en el derecho indiano, como pudo ser la manumisión de Josefa Sáez, luego que, ante la nula referencia testamentaria, varios testimonios confirmaran la intención de su dueño, ${ }^{49}$ otros supuestos apuntan a resistencias sociales en admitir el fin de los castigos corporales. Al dirimirse una deuda, surgió entre otras causales, el hecho probado de que Juan Tamayo había azotado al indio Juan Ortega. Se alegó que los azotes, ordenados por el provisor y vicario general del obispado, buscaban corregir una conducta matrimonial poco acorde con la moral cristiana. Este castigo no contravenía los principios constitucionales, ya que la prohibición sólo se refería a actos en lugares públicos y no a la relación

45 ARAy, LC 17, LDC2. Cecilia Pérez contra Bartola Medina por adulterio y torpe trato con su marido Ignacio Oré, enero de 1824.

46 Ibidem. María Guerrero contra Catalina Reyes, octubre de 1820; LDC1. Eduarda Bellido contra Isabel, Paula Berrocal y Pascuala Roxas, noviembre de 1821

47 ARAy, LC 17, LDC2, Diligencia, alcalde 2. ${ }^{a}$ nominación, enero de 1821.

48 Archivo General de la Nación, Perú (en adelante AGNP), Superior Gobierno, 189, 1183, 31.

49 Ibidem. Petición de Josefa Sáez para ser manumitida, febrero de 1822. 
entre patrones y criados, y menos a la que tenía derecho un padrino de casamiento, cuando textualmente «es costumbre que estos a los ahijados indios los suele corregir con azotes». Ante tal defensa de la primacía del derecho consuetudinario coactivo en la esfera privada, la contraparte insistió en la vigente abolición constitucional de cualquier corrección física, recriminando una actuación sin apoyo en sentencia firme, agravada por el hecho de que «los azotes han caído sobre un español que está en el goce del derecho de ciudadano». ${ }^{50}$

El grueso de las causas civiles pueden clasificarse como discordias en torno a legados testamentarios, litigios por el uso y disfrute de propiedades, tanto urbanas como rurales, deudas de toda índole, incluidas a la hacienda pública, ${ }^{51}$ pero sobre todo relativas a arrendamientos, documentos de fianzas — cartas de libranza, obligaciones-, e intereses atrasados de obras pías, capellanías o censos consignativos. No entraremos en los detalles del conjunto de las conciliaciones, sino sólo de aquellos que nos puedan ayudar a comprender el trasfondo de los conflictos y cambios que se estaban produciendo en Huamanga durante la etapa estudiada.

La defensa de los derechos de propiedad fue un tema recurrente. En varios casos se percibe cierta tensión entre estos y los de usufructo o tenencia más o menos precaria, tanto en lo relativo a aposentos o recámaras, ${ }^{52}$ como por servidumbres de paso hacia casas y cuartos o por callejones, viales o corralitos que no siempre estaban bien delimitados. ${ }^{53}$ Los alcaldes intentaban racionalizar el confuso entramado urbano y la difícil convivencia vecinal que ocasionaba, cuando exigían que se cumpliera una venta comprometida verbalmente con el argumento de que en caso contrario los afectados no dispondrían de «luz y ayre», ${ }^{54}$ o cuando desahuciaban a unos inquilinos de tiendas abiertas en la fachada de una casa para frenar todo escándalo público. ${ }^{55}$

50 ARAy, LC 17, LDC2. Francisco Ortega, indio de la Parroquia de Santa Ana, contra Juan Tamayo, noviembre de 1821.

51 ARAy, LC 17, LDC1. Hacienda Nacional contra la testamentaría de Narciso Basagoitia, intendente interino de Puno, julio de 1821; y contra el regidor Marcos Espinosa por el resto pendiente de los tributos del semestre de San Juan de la doctrina de Tambillo, abril de 1821.

52 Ibidem. Julián Barsola contra Feliciano Salguero, octubre 1821. Los aposentos eran parte de un edificio denominado genéricamente casa, compuesto de varias estancias comunicadas o no entre sí, que se habrían a un patio o huerta común.

53 Ibidem. Agueda Gutiérrez contra Narcisa de la Cruz y de la misma contra Martín Palomino, febrero de 1821 y diciembre de 1823.

54 Ibidem. Pedro Zorraquín Enzaya contra Bernardo Sánchez y Martina Guillen, mayo de 1821.

55 Ibidem. Felipa Cruzat contra Casimiro Carrillo, julio de 1921. 
Mayor entidad tuvieron las discordias en torno a la propiedad o su tenencia, arrendamientos y mejoras o cargas que pesaban sobre fincas rurales situadas en zonas próximas a la jurisdicción de la ciudad, que se extendía hasta el río Huatatas o Acos Vinchos. Sin embargo, al primar la vecindad de las partes, también se dirimieron asuntos sobre propiedades en la zona de Cangallo, Huanta o el valle del río Apurímac ${ }^{56}$ lo que dio pie a ciertos conflictos de jurisdicción entre alcaldes y jueces letrados de partido, como muestra el caso de Catalina Hernández contra el arrendatario de su hacienda Yamaná, Marcos Córdova, quien siendo vecino de Huamanga escapó a Huanta para huir de toda responsabilidad, treta que el alcalde atribuía a su condición de abogado. ${ }^{57}$ Asimismo, normas imprecisas de tenencia de la tierra o cierta presión indígena sobre espacios agrícolas pudieron determinar la solicitud de amparo de los indios de Chiara para consolidar su derecho preferente al del hacendado de Maray-Vilca, Jacinto Infanzón, resuelto con una providencia favorable justificada en que «por ley estaban obligados los jueces a amparar en su posesión a los que estuvieren, aunque ella sea poco legal». ${ }^{58}$

Las reclamaciones de alquileres atrasados también estuvieron a la orden del día. Se exigió la cancelación de cuotas pendientes por las haciendas Pampay, ${ }^{59}$ Acchapa o Guallcapuro, en noviembre de 1822, febrero y abril de 1823 respectivamente; el propio ayuntamiento en 1820 reclamó a Bartolomé Herrera la renta por la gestión de las laderas urbanas; ${ }^{60}$ conventos como el de Santo Domingo y Santa Teresa pidieron, en septiembre de 1822 y marzo de 1824, el estricto cumplimiento de los contratos enfitéuticos suscritos respectivamente en la hacienda Yucay y el obraje y hacienda ganadera Caramarca, o su reversión. ${ }^{61} \mathrm{El}$ creciente endeudamiento de los tenedores de fincas ${ }^{62}$ se atri-

56 Ibidem. Basilio Palomino contra Juan Alarcón, junio de 1821.

57 ARAy, LC 17, LDC2. Bernardino Cevallos contra Marcos Córdova, junio de de 1821.

58 ARAy, LC 17, LDC1. Indios de Chiara contra Jacinto Infanzón, junio de 1822. Como resultado de los derechos sobre las tierras de Ataquisuar concedidos a los indios, se abrió otra causa en: LDC2. Manuel Vellido contra Jacinto Infanzón, abril de 1823. Ubilluz.

59 ARAy, LC 17, LDC2. Demanda ejecutiva de Felipa Salcedo de la Hermosa contra Francisco 1822.

60 Ibidem. Síndico Procurador D. D. José Matías León contra Bartolomé Sierralta, enero de

61 Ibidem. Convento de Santo Domingo contra los herederos del finado Juan Figueroa y contra el tutor y curador de ellos y albacea Pedro de la Hermosa, agosto de 1822; LCD1. Cayetano Medina y Urquizo, síndico Procurador de las rentas del Monasterio de Santa Teresa contra María Carmen Cáseres, viuda y albacea Gaspar Villalva y Mendieta, marzo de 1824.

62 ARAy, LC 17, LDC2. Martina González contra María Josefa San Juan, febrero de 1822. Demandas ejecutivas de Juana de Eyzaguirre contra Juan Miguel de Ayarza y su esposa María Josefa Carrasco, septiembre de 1822; y de Felipa Salcedo de la Hermosa contra Francisco Ubilluz, noviembre de 1822; Pedro Meneses contra Francisco Velarde, febrero de 1824. 
buyó a los efectos adversos de las abundantes lluvias de 1817, que afectaron sobre todo los cultivos ribereños del Huatatas, ${ }^{63}$ y a los efectos de la guerra, cuando la región devino en escenario bélico o se volvieron hechos cotidianos la presencia de tropas y actos como la confiscación de ganado, ${ }^{64}$ apropiación de pastos para alimentar caballos y mulas del ejército ${ }^{65}$ o destrozos en los cultivos. Así cuando Catalina Hernández exigió, entre 1817 y 1822, que los arrendatarios de la hacienda Yamaná se pusieran al corriente de pago, a lo ya apuntado uno de ellos añadió como descargo el «raro contingente cual es la guerra», ${ }^{66}$ considerando que las pérdidas debían ser asumidas en parte por la propietaria. Las secuelas de la guerra también afectaron a los propietarios urbanos, que vieron confiscadas temporalmente casas o fincas destinadas al alojamiento de tropas, sin que se les resarciera convenientemente o se les aclarase si era el ayuntamiento o la hacienda nacional quien debía responsabilizarse de los costos o desperfectos. ${ }^{67}$

Un número considerable de conciliaciones evidencian crecientes dificultades por cancelar deudas contraídas para financiar actividades comerciales —obligaciones o fianzas - o agrarias — censos consignativos. Así varios comerciantes no pudieron cumplir con obligaciones o vales de fianza suscritos contra los beneficios esperados en el tráfico de tocuyos, maíz, azúcar, aguardiente o piñas de plata, debido a la quiebra de los circuitos de intercambio hacia la costa o hacia las comarcas serranas vecinas de Cangallo, Andahuaylas o Pasco. ${ }^{68}$ La mayoría de las reclamaciones tuvieron que ver con deudas de intereses no cancelados oportunamente de obras pías,

63 Ibidem. Francisco Hernández, por su madre política María Paula Oré, contra Leonardo Guillen, abril de 1823 .

64 Ibidem. Matías Vivanco pide se le libere de reponer el ganado sustraído o saqueado por los disidentes de Cangallo en el Ato Mansanayoc, doctrina de Vischongo, partido de Vilcashuamán, julio de 1822 .

65 Ibidem. Josefa Palomino, viuda de Francisco de Paula Pruna, asesor general del virreinato, contra Micaela y Margarita Jordán, abril 1823. Tras ajustar cuentas, la parte deudora prometió cancelar su deuda cuando lo hiciera a su vez la Caja Nacional «de lo contrario quedan condonados y cancelados».

66 Ibidem. Bernardino Estébanez de Cevallos sucesivamente contra José Paredes, Marcos Córdova y Bienes de Isabel Allende, esposa del arrendatario Juan Alarcón, abril, junio y noviembrediciembre de 1821.

67 Ibidem. María Gutiérrez Calle contra los Fondos del Ayuntamiento, febrero de 1822.

68 ARAy, LC 17, LDC1. Demandas de María Godoy contra Ana Espinoza, viuda de Alexo Antay, setiembre de 1822; del regidor constitucional Gregorio Flores contra Nicolás Muñoz y María del Pozo, enero de 1823; de Celedonio Barbarán contra Ambrosia Basquez y herederos de Tomás Ramírez, julio de 1823; de Rafael Muñoz contra Domingo Núñez, marzo de 1824; y LDC2, de María Gutiérrez de la Calle contra el presbítero Faustino Alfaro y a Felipe Pilares su fiador, marzo de 1822; de Mateo Chilengano contra Petrona Ramírez, febrero de 1822. 
buenas memorias, capellanías y, sobre todo de censos consignativos, que llegaron a acumular años sucesivos de impagos. Todo parece indicar que hubo un creciente problema en el pago de estos. Frente a sólo dos demandas por tal motivo en la primera etapa liberal, ${ }^{69}$ durante el Trienio Constitucional los conventos de San Francisco, ${ }^{70}$ San Juan de Dios, ${ }^{71}$ la Merced, ${ }^{72}$ Santa Clara, ${ }^{73}$ la Cofradía del Santísimo Sacramento ${ }^{74}$ o diversos eclesiásticos a título individual ${ }^{75}$ actuaron contra sus deudores, propietarios de fincas urbanas o agrarias, como las haciendas de Putaca en Cangallo del marqués de Valdelirios, Huacahuara de las hijas y herederas de José Pareja, Yamaná la Baja de Mariano Alvarado o el cañaveral de Llamoctachi de Cayetano López del Hierro. En general, los censos oscilaban entre los mil y los dos mil doscientos pesos, destacando con mucho los veinte mil pesos impuestos sobre la hacienda cañaveral de Llamoctachi. Algunas explotaciones, como Yamaná de José María Palomino o Huamancocha de José Gálvez, en 1821 acumulaban casi una década de atrasos en el abono de los intereses preceptivos, ${ }^{76}$ si bien el promedio de cuotas pendientes de cancelación se situaba entre las seis y siete anualidades.

Las alegaciones de los demandados apuntan a una situación condicionada por un enfrentamiento sustancial ente censualistas y censatarios. Los deudores de cuatro capellanías impuestas sobre fincas urbanas o haciendas como la de Cayarpachi pidieron una quita en la deuda y se excusaron en las

69 Ibidem. Melchora de Jesús, religiosa monasterio de Carmelitas Descalzas, contra el albacea del presbítero Gabriel Villavicencio; LCD1. Pedro Illanes y Cipriana Chávez se enfrentaron en parte por los intereses no cancelados al convento de San Francisco por un censo sobre una propiedad mancomún en Palca.

70 ARAy, LC 17, LDC1. Convento de San Francisco contra el platero Manuel Palomino, en noviembre de 1822 .

71 ARAy, LC 17, LDC2. Hospital de San Juan de Dios contra Norverto Bendezú; y LCD1, contra el marqués de Feria y Valdelirios, en febrero y noviembre de 1821.

72 ARAy, LC 17, LDC1. Convento de la Merced contra el coronel José Palomino, en julio de 1822.

73 ARAy, LC 17, LDC2. Convento de Santa Clara contra Cayetano López del Hierro, en julio de 1822 y abril de 1823; LCD1, desavenencia entre el convento de Santa Clara y el hacendado Ignacio de Oré, marzo de 1822.

74 ARAy, LC 17, LDC2. La Cofradía del Santísimo Sacramento contra Mariano Alvarado, en mayo de 1822.

75 Ibidem. El deán dr. don Tomás López de Ubillas contra María Enciso, heredera de Alejo Enciso, en octubre de 1822; Casimiro Cerbantes, cura interino de Tambo, contra los herederos del anterior cura dr. don Calixto Cárdenas y Berrocal. La madre soror Isabel de la Encarnación Palomino y Paredes contra las hijas y herederas de José Pareja, en enero de 1822.

76 ARAy, LC 17, LDC1. José Pastor León, prebendado de la catedral y colector de la obra pía instituida por Bernardino Altolaguirre en beneficio de los indios de Castrovirreyna por los réditos los censos impuestos en las haciendas Yanamá y Huamancocha, febrero y abril de 1821. 
dificultades surgidas por «la situación del tiempo». ${ }^{77}$ Según María Eusebia Laynes, al estimarse su deuda no se tuvo presente el mal estado de la finca por haber servido de cuartel de las tropas disidentes, ni la rebaja del interés del 5 al 3\% «concedida esta gracia por el Soberano». ${ }^{78}$ Juan García de los Godos, hombre bueno de José Palomino, ${ }^{79}$ consideró que el tenor de la Real Cédula de 22 de marzo de 1816 era rebajar provisionalmente los intereses de los censos e iniciar un proceso informativo para, a la luz de los argumentos y posiciones recopiladas, convertir la medida en definitiva. Una postura que devino colectiva cuando varios propietarios pospusieron los pagos de los intereses o decidieron abonar sólo el 3\%, afectando sobre todo esta postura de facto a gentes e instituciones del mundo eclesiástico local. La medida de presión se tomó en una coyuntura en la que el gobierno virreinal, acuciado por las necesidades bélicas, había confiscado las rentas de las capellanías y, al socaire de la revolución liberal, aplicado la Reforma de Regulares de 1820, que supuso la sujeción de las órdenes a los respectivos obispos, la supresión de los conventos con menos de ocho religiosos y la nacionalización de sus bienes, que en el caso de Huamanga afectó al menos al hospital de San Juan de Dios y a sus bienes y rentas. ${ }^{80}$ Entre tanto el obispado estuvo bajo la supervisión de un administrador eclesiástico, ya que el obispo Pedro Martínez de Cos, sorprendido en su visita pastoral por la campaña del general Álvarez Arenales, se había refugiado en Lima, desde donde sería desterrado por San Martín. ${ }^{81}$ La respuesta de los censualistas para forzar el reintegro de los intereses al 5\%, o, cuando no fuera posible, resarcirse con la subasta de las propiedades, fue

77 ARAy, LC 17, LDC2. Demandas por réditos vencidos a Juan de Dios Muñoz por una capellanía detentada por Feliciano Vergara, abril de 1821; de Baleriana Galindo contra Petrona Palomino, personera de su hijo político Marcos Pantoja, por la instituida por el presbítero Bernardo Muñoz Galindo, junio de 1821; de Vicente Fuentes cura de Chuschi, por la instituida por el deán de la catedral Gaspar Ortiz de Espinoza, en febrero y junio de 1823.

78 ARAy, LC 17, LDC2. José Álvarez a nombre de Nicolás Benítez contra María Eusebia Laynes, viuda de Vicente de la Moya por los réditos atrasados de una obra pía instituida por Antonio López Vellido a favor del maestro de primeras letras de Huanta, julio de 1822.

79 José Palomino de Mendieta detentaba en 1823 las haciendas Yanamá y Tartaria y el molino Canónigo, con alfalfares y tierras de Yanamilla, tasado respectivamente en 2.500, 2.000 y 10.000 pesos; en 1828 constaba a su nombre la hacienda Carhuaschoque, sobre la que el convento de Santa Clara tenía impuesto un censo de 1.000 pesos, y un molino en la ribera del Huatatas; participó, como coronel de milicias, en la acción contra los montoneros patriotas en las punas de Lauricocha en julio de 1824; y fue alcalde en 1806 y 1824; referencias en: ARAy, Intendencia, Asuntos Administrativos, leg. 40, Cuaderno n. ${ }^{\circ}$ 42; Peralta, 2001, 21 y 27; CDIP, XXII (3), 236; Varela, 1907, II, 389.

80 Sala i Vila, 2009, 223-250 y 2011, 718.

81 Hernández, 2008. 
recurrir a la vía judicial contra los deudores, con la salvedad de que el nuevo principio constitucional les obligaba a renunciar al fuero eclesiástico en tales asuntos y a sujetarse a la conciliación como cualquier otra persona o institución.

En paralelo, los censatarios presionaron políticamente para lograr la rebaja definitiva de los intereses que gravaban los censos consignativos, lo que ha sido señalado por Marie Laure Rieu-Millán como la principal reivindicación en temas vinculados a la agricultura expresada durante el primer liberalismo por las regiones andinas. ${ }^{82}$ En realidad, desde la década de 1780, sucesivas peticiones habían llegado a la Corona suscritas por hacendados, como los de los valles de Lima y Trujillo, o autoridades, como el visitador Jorge Escobedo en 1784 o el intendente de Huamanga, Demetrio O'Higgins en $1802 .{ }^{83}$ Durante el primer liberalismo, el cabildo del Cusco la incluyó en 1811 entre las instrucciones a sus diputados a Cortes $;{ }^{84}$ la defendieron los representantes de Chile en 1812 y los de Charcas y Trujillo, Mariano Rodríguez Olmedo y Pedro García Coronel, en 1813. El retorno al absolutismo no supuso en ningún caso el abandono de las reclamaciones. El amplio movimiento reivindicativo continuaría entre 1814 y1820 cuando, tras la disolución de las Cortes, Fernando VII permitió en junio de 1814 que los diputados americanos permanecieran en la Península en defensa de las peticiones e instrucciones que les habían dado sus respectivas ciudades y provincias.$^{85}$ El diputado Martín José Mújica, siguiendo las instrucciones de los ayuntamientos de Huamanga y Huancavelica y como un medio para superar la crisis agraria y minera regional, solicitó en 1816 la rebaja definitiva, o en su defecto por diez años, de los intereses de los censos redimibles abonados en dinero. ${ }^{86}$ El cabildo de Huamanga describía, en sendas peticiones de 1814 y 1815 , una situación dominada por el creciente endeudamiento de las propiedades urbanas y rurales debido a los cortos márgenes de beneficios de las explotaciones agrarias, a la política metropolitana de consolidación de vales reales llevada a cabo en la década precedente ${ }^{87} \mathrm{y}$

82 Rieu-Millán, 1990, 184.

83 Fisher, 1981, 165-166.

84 BNP, Manuscritos Virreinato, D 334, citado por Rieu-Millán, 1990, 25

85 Orden Circular de 17.6.1814 y Zárate, 1988.

86 AGI, Lima, 602, Consejo de Indias en Sala segunda, 17.1.1816, vista la representación de Mujica de 24.9.1816.

87 No existe estudio alguno que evalúe su alcance en el Perú, que aportó en torno a 1.400 .000 pesos, un $10 \%$ del total de Indias. Para el caso del virreinato de Nueva España y su relación con el proceso de Independencia véase Wobeser, 2006. 
a los ecos regionales de la rebelión cuzqueña de $1814{ }^{88}$ En parecidos términos se expresaron el diputado Mariano Rivero siguiendo instrucciones del cabildo de Arequipa, ${ }^{89}$ el oidor decano de la audiencia del $\mathrm{Cusco}^{90}$ y los hacendados de Trujillo. ${ }^{91}$ La Corona accedería en 1816 finalmente a reducir al 3\% los intereses de censos redimibles abonados en efectivo por un periodo de cuatro años en Huamanga, Huancavelica y Trujillo ${ }^{92}$ y por diez años en Charcas, donde una iniciativa de los vecinos de Cinti, Tarija y Potosí dio lugar a la elaboración de un expediente (1796-1815) cuyas conclusiones se incluyeron en las instrucciones dadas a su diputado Mariano Rodríguez de Olmedo, obispo electo de Puerto Rico. Además, para resolver si era o no conveniente consolidar la rebaja de intereses, se ordenaba iniciar expedientes informativos para que instituciones y propietarios pudieran defender sus pareceres e intereses.

La reivindicación de la rebaja de los intereses de los censos consignativos siguió manifestándose en diversas regiones andinas durante el Trienio Constitucional. Sabemos que lo solicitaron los censatarios de Andahuaylas en $1822,{ }^{93}$ y la diputación provincial de Charcas, que trasladó el sentir de los ayuntamientos de La Plata, Potosí, Cochabamba, La Paz, Misque, Oruro y Santa Cruz de la Sierra. Salvo para esta última y para toda la región del Oriente, se describió una difícil situación dominada por el creciente endeudamiento de las propiedades urbanas, rurales, ingenios mineros e instituciones de gobierno a causa de las constantes exigencias desde 1809 de donativos voluntarios, arbitrios y contribuciones extraordinarias para afrontar los costes bélicos. ${ }^{94}$ A ello se sumaba la falta de mano de obra a raíz de las sucesivas levas y la abolición de la mita, la caída de la demanda y de los precios agrícolas, el declive minero, agravado por la escasez de azogues, la quiebra de circuitos comerciales, y la migración de un número

88 AGI, Lima, 602, Ayuntamiento de Huamanga, 24.9.1814, citado por Hamnett, 1978, 126-128.

89 AGI, Lima, 799, Informe del diputado por la provincia de Arequipa Don Mariano Rivero sobre sus solicitudes relativas a gracias, 15.9.1817.

90 AGI, Lima, 774, Del oidor decano a S.M., Cuzco, 14.3.1819, en Hamnett, 1978, 128.

91 AGI, Lima, 602, Consejo de Indias en Sala Segunda, 7.2.1816.

92 Hamnett, 1978, 126-128.

93 ARC, Intendencia, Gobierno, leg. 151, 1816-1818, Sobre rebaja de censos, citado por Burns, 2008, 246-247.

94 En especial se lamentaban de los recientes gravámenes del $20 \%$ a los productos de consumo o, en el caso de la coca de los yungas paceños, del $40 \%$ al propietario de la finca y un $48 \%$ al rescatador. 
no desdeñable de vecinos. Había sido en tal situación de penuria cuando los «despiadados censualistas» habían recurrido a la justicia, con sus secuelas de altos costos judiciales y embargos. La diputación provincial no veía otra solución a las dificultades que afrontaban los censatarios que rebajar los intereses y condonarles las deudas acumuladas hasta 1817, y que, una vez concluida la guerra y pacificado el virreinato, se llegara con los censualistas a una «moderada composición sobre capitales según el estado de las fincas»..$^{95}$

Llegado a este punto, es bueno recordar que los censos consignativos tenían una característica dual. Se trataba de contratos privados entre partes, en los que la Iglesia, y en particular las órdenes religiosas, fueron actores clave. Sin embargo, el interés nominal era regulado rígidamente por la Corona. La política borbónica tendió a rebajarlos al 3\% en distintos contextos para sumar apoyos, como muestra que Felipe V los modificara en 1705 en la Corona de Castilla y Fernando VI en la Corona de Aragón —donde eran denominados censales — en $1750,{ }^{96}$ manteniéndose sólo tasas del $5 \%$ en los territorios coloniales americanos. Esta diferencia en el gravamen debería ser un tema de investigación que nos permitiría comprender las características y determinantes en el crédito colonial y cierta sensación de agravio comparativo en el trasfondo de las reclamaciones de los propietarios andinos. A priori debemos señalar que, si la temprana medida tomada por Felipe $\mathrm{V}$ se inscribía dentro de su política de lograr apoyos entre sectores de propietarios y censualistas en el contexto de la Guerra de Sucesión, ${ }^{97}$ bien podemos presuponer que Fernando VII, cuando concedió su rebaja temporal en 1816, buscaba asimismo ampliar las bases de apoyo a la causa realista en las contingencias adversas de las guerras por la independencia en América.

Diversos autores han señalado una vía de interpretación para la España peninsular que nos puede ayudar a comprender el contexto de las reclamaciones agrarias andinas. Según Bartolomé Yun, la coyuntura peninsular de fines del siglo XVIII se caracterizó por la tendencia a la baja de la rentabilidad agraria, pero sobre todo por el declive progresivo y paralelo de otras fuentes de ingreso típicas del Antiguo Régimen como lo fueron los censos consignativos. Se trataba del agotamiento, dentro de su propia diná-

95 Diputación Provincial de la Plata, 20.7.1822, en Goicochea, 1979, 1-6.

96 Tello, 2004 y 2007; Fernández, 1985; García, 1961; Ferrer, 1983.

97 Peset, 2007, 211-236. 
mica, de un modelo de desarrollo histórico que llevó a su vez a una crisis definitiva de las relaciones sociales que lo sostenían. ${ }^{98}$ Ricardo Robledo ha señalado como para la nobleza castellana el censo consignativo por debajo del $3 \%$ dejó de ser el recurso habitual de crédito en momentos en que los campesinos resistían de diversas formas el pago de los derechos señoriales o de la propiedad. La negativa de los campesinos al pago de diezmos, censos y rentas de la tierra a diversas instituciones eclesiásticas coincidió con la de los señores al pago de los intereses de los censos. ${ }^{99}$ En palabras de Enric Tello el sistema hipotecario censitario del Antiguo Régimen no se hundió por si mismo, ni como consecuencia de la intervención de la monarquía absoluta, sino que, como en el caso de los diezmos, fue destruido por quienes se resistieron a seguir pagando los intereses, porque en caso contrario se habrían vistos abocados a la quiebra, sojuzgados por las obligaciones de la renta territorial, del interés de los censos, de las exigencias señoriales y de una fiscalidad pública en aumento. La legislación liberal no habría sido sino una vía que permitió recomponer el orden social y liberar la tensión de otra forma insoluble. ${ }^{100}$

Tras la independencia peruana, el primer congreso constituyente suspendió el 31 de mayo de 1823 cualquier orden ejecutiva de cobro de los intereses de los principales impuestos sobre fincas rústicas o urbanas ${ }^{101}$ a raíz de las peticiones del diputado por Trujillo, Justo Figuerola, y de la municipalidad de Piura. ${ }^{102}$ Dos años después, el ministro de Hacienda del gobierno de Bolívar, Hipólito Unánue, tras oír el dictamen de la comisión de Justicia y Legislación y conocer los informes de diversas instituciones, como los de la municipalidad del Cusco, ${ }^{103}$ fijó su tipo de interés en el $2 \%$ y $3 \%$ según se tratara de fincas o urbanas, valores que se mantuvieron constantes a lo largo del siglo XIX. ${ }^{104}$

98 Yun, 1995, 879.

99 Robledo, 1991, 246, 247 y 261.

100 Tello, 2004, 146.

101 Archivo de la Legislación Digital del Perú (en adelante ALDP), L 31.5.1823. www.congreso. gob.pe.

102 Sesiones 11.3 y 24.5.1823 en CDIP, XV (1), 359.

103 Archivo de Límites del Ministerio de Relaciones Exteriores, Caja 263, CC292, Expediente para que se informe al Gobierno Supremo sobre la orden de rebaja de los censos que indica el decreto del 22 de abril. Cusco, 1825.

104 ALDP, Dictamen de 10.3.1825, Decreto de 22.4.1825 y Armas, 2008, 167. La norma sería extensiva en Bolivia por la Orden de 6.12.1825 en que se resolvió observar los decretos expedidos en el Perú a 31.5.1823 y 22.4.1825. 


\section{Un balance de la justicia conciliatoria municipal y una coda}

Más allá del debate de si la justicia conciliatoria, como otras tantas aportaciones de la Constitución de 1812, fue consecuencia de una larga tradición o de innovaciones que surgieron de los debates de las Cortes, ${ }^{105}$ nos interesa señalar varios factores que han ido surgiendo a lo largo del presente artículo. El modelo de conciliación liberal suponía una cierta inflexión en la concentración de poderes que había caracterizado al viejo cabildo, como consecuencia del hecho de que la conciliación no era entendida como un juicio en estricto sentido. La justicia lega sólo sobrevivía en pueblos y ciudades ejercida por los alcaldes, en tanto que la justicia letrada se imponía en los partidos, las provincias y las audiencias. El modelo de arbitraje se mostró como un mecanismo de intermediación y de búsqueda de engranajes de cohesión social. ${ }^{106}$ Quizás el caso de los conflictos en torno a las deudas por intereses de censos nos aporta el ejemplo más ilustrativo de cómo las corporaciones locales asumieron posiciones políticas que eran coherentes con su experiencia acumulada en las conciliaciones. En conjunto no hay evidencias de que los alcaldes de Huamanga favorecieran a censatarios o censualistas en sus dictámenes, ya que según los casos, optaron por exigir la cancelación de los intereses con cierta quita, ordenaron el embargo de ciertas fincas ${ }^{107} \mathrm{o}$ la subasta de la propiedad para cubrir lo adeudado. Y sin embargo las instituciones locales y los representantes provinciales se erigieron en portavoces políticos y defensores de los intereses de los endeudados detentadores de fincas ante las Cortes españolas, la Corona, o los congresos constituyentes peruanos de 1823 y 1828 . Anotemos aquí un breve inciso, se actuó corporativamente desde el cabildo en las etapas absolutistas y a través de los diputados a Cortes o de la diputación provincial en los periodos constitucionales. Los ayuntamientos, cuando optaron por reivindicar el desarme de los principios que habían sostenido el crédito durante el Antiguo Régimen colonial, se convirtieron en la práctica en decididos defensores de los principios liberales y, quizás por ello, hemos podido probar la trayectoria liberal y republicana de varios de los actores implicados en las conciliaciones.

105 Tales tesis han sido defendidas desde la historia del derecho constitucional por autores como Garriga y Lorente, véase Garriga (coord.), 2010.

106 Guarisco, 2003 lo ha señalado para el caso estrictamente indígena.

107 ARAy, Libros de Cabildo leg. 17, LDC2. Manuel Mavila contra María Enciso por los réditos de 2.000 pesos de una Buena Memoria. 
En Bolivia y el Perú el temprano republicanismo asumió en cierta medida los principios jurídicos del liberalismo hispano. En Bolivia, los decretos de 15 y 21 de diciembre de 1825 daban lugar a la creación de una Corte Superior de Justicia en La Paz con las mismas atribuciones que las antiguas audiencias y mantenían vigente el Reglamento de Tribunales de 9 de octubre de 1812 y demás decretos de las Cortes españolas relativos a la administración de justicia. Se conservaba la influencia liberal hispana en la ley Sobre los procedimientos de la administración de justicia ( 8 de enero de 1827), cuyos artículos 117, 133 y 134 establecían la existencia de jueces de paz, encargados de dirimir en conciliaciones las causas civiles y de injurias, excluyendo expresamente la posibilidad de que hubiera aforado alguno. ${ }^{108}$ En el Perú, las constituciones de 1823, 1826 y 1828 coincidieron en atribuir a alcaldes y regidores, en ocasiones considerándoles jueces de paz, el principio y actuación de la conciliación entre vecinos enfrentados, un trámite inexcusable para poder apelar a cualquier instancia judicial letrada. ${ }^{109}$ En Ayacucho, durante la vigencia de la Constitución de 1828, las conciliaciones se registraron en los mismos libros de actas abiertos a partir de la entrada en vigor de la Constitución de 1812 que hemos estado analizando. Un dato que por si mismo evidencia hasta que punto, para los contemporáneos, se trataba de una medida heredada y continuista del liberalismo hispano. En conclusión, en el contexto de las guerras de Independencia se dirimió la voluntad y el derecho de construir un Estado propio por parte de los peruanos, pero al mismo tiempo tuvo lugar un largo conflicto entre quienes querían desarbolar el antiguo sistema y quienes querían consolidar una sociedad basada en los principios del liberalismo.

Recibido el 01 de septiembre de 2012

Aceptado el 16 de octubre de 2012

108 www.gacetaoficialdebolivia.gob.bo/normas/verGratis/56377.

109 ALDP, Constitución Política de 1823, Capítulo X, Arts. 142 y 143; Constitución de 1826, Capítulo V, De la Administración de Justicia, Arts. 112-4; Constitución de 1828, De la administración de justicia, Arts. 120 y 121. Díaz, Ruz y Galdames, 2011 analizan su trascendencia en Arica y Tarapacá como un proceso original del constitucionalismo peruano. 


\section{Bibliografía}

Annino, Antonio: «La ruralización de lo político», en Annino, Antonio (coord.), La revolución novohispana, 1808-1821, CIDE, FCE, INEHRM, FCCM, 2010, 384-464.

Armas, Fernando: «Iglesia, Estado y economía en la coyuntura independentista en el Perú», Anuario de Historia de la Iglesia 17, 2008, 163-177.

Barriera, Darío G.: «Justicia, jueces y culturas jurídicas en el siglo XIX rioplatense», Nuevo Mundo, Mundos Nuevos (on line) 23 de marzo, 2010.

Burns, Kathryn: Hábitos coloniales. Los conventos y la economía espiritual del Cuzco, Lima, Quellca/IFEA, 2008.

Castillo, F., Figallo, L.J., y Serrera, L. J.: «La Geografía del Perú de 1814 y las Cortes de Cádiz y la última geografía del Perú colonial (1814)», en Las Cortes de Cádiz y la Imagen de América, Cádiz, Universidad de Cádiz, 1994, 397-504.

Colección Documental de la Independencia del Perú (CDIP), XV, Primer Congreso Constituyente; XXII, 3, Documentación Virreinal del Cuzco, Lima, Comisión Nacional del Sesquicentenario de la Independencia del Perú, 1973.

Chiaramonti, Gabriela: «De marchas y contramarchas: apuntes sobre la institución municipal en el Perú, 1812-1861», Araucaria, 18, 2007, 150-170.

Díaz, Alberto, Ruz, Rodrigo y Galdames, Luis: «Participación de la población indígena de Arica y Tarapacá en la política y la justicia comunitarias durante el siglo XIX», Revista de Estudios Histórico-Jurídicos, XXXIII, 2011, 511-532.

Fernández de Pinedo, Emiliano: «Del censo a la obligación: Modificaciones en el crédito rural antes de la primera guerra carlista en el País Vasco», en García Sanz, Ángel y Garrabou, Ramón (eds.): Historia agraria de la España contemporánea. I: Cambio social y nuevas formas de propiedad (1800-1850), Barcelona, Crítica, 1985, 297-305.

Ferrer Alòs, Llorenç: «Censals, vendes a carta de gràcia i endeutament pagès al Bages (s.XVIII)», Estudis d'Història Agrària, 4, 1983, 101-128.

Fisher, John R.: Gobierno y sociedad en el Perú Colonial: El Régimen de las Intendencias, 1784-1814, Lima, PUCP, 1981.

Florez, Pedro G.: Guía de Forasteros del departamento del Cuzco, dividida en tres partes; política eclesiástica y militar, para el año de 1834, Cuzco, Imp.M. Corral, 1834.

Fradkin, Raúl O. (comp.): El poder y la vara. Estudios sobre la justicia y la construcción del Estado en el Buenos Aires Rural (1780-1830), Buenos Aires, Prometeo, 2008.

Gamio, Fernando: La municipalidad de Lima y la emancipación, 1821, Lima, Sanmartí y Cía., 1944. 
García i Sanz, Arcadi: «El censal», Boletín de la Sociedad Castellonense de Cultura, XXXVII, 1961, 281-310.

Garriga, Carlos (coord.): Historia y Constitución. Trayectos del constitucionalismo hispano, México, CIDE-CM-CMichoacán-Instituto Mora, 2010.

Goicochea, Álvaro: Documentos sobre el sector urbano en Bolivia (1756-1877), Lima, Biblioteca Andina, 1979.

González, Enrique, Gutiérrez, Yuri y Urrutia, Jaime: La ciudad de Huamanga: espacio, historia y cultura, Lima, UNSCH, Concejo Provincial de Huamanga, Centro Peruano de Estudios Sociales, 1995.

Guarisco, Claudia: Los Indios del valle de México y la construcción de una nueva sociabilidad pública, 1770-1835, Zinacantepec, El Colegio Mexiquense, 2003.

Hamnett, Brian R.: Revolución y contrarrevolución en México y el Perú, México, FCE, 1978.

Hernández, Elizabeth: «"Una columna fortísima del altar y del trono”: Pedro Gutiérrez de Cos, obispo de Huamanga y de Puerto Rico (1750-1833)», Hispania Sacra, 60, 122, 2008, 531-555.

Igue, José Luis: Bandolerismo, patriotismo y etnicidad poscolonial: los 'morochucos' de Cangallo, Ayacucho en las guerras de independencia, 1814-1824, Lima, PUCP, Tesis de Licenciatura en Historia, 2008.

Martínez Pérez, Fernando: Entre confianza y responsabilidad. La justicia del primer constitucionalismo español (1810-1823), Madrid, Centro de Estudios Políticos y Constitucionales, 1999.

Morell Ocaña, Luis: «El municipio constitucional y la Instrucción de 1813», en El Municipio Constitucional, Madrid, Instituto Nacional de Administración Pública, 2003, 121-146.

Morelli, Federica: «Pueblos, alcaldes y municipios: la justicia local en el mundo hispánico ente el Antiguo Régimen y Liberalismo», Historia Crítica, 36, 2008, 36-57.

Ortíz, Juan y Serrano, José Antonio (eds.): Ayuntamientos y liberalismo gaditano en México, Zamora, El Colegio de Michoacán, Univ. Veracruzana, 2007.

Paniagua, Valentín: Los orígenes del gobierno representativo en el Perú. Las elecciones (1809-1826), Lima, PUCP-FCE, 2003.

Peralta, Luz: Censos y capellanías de las casas religiosas de Ayacucho y Huancavelica, Lima, UNMSM, Seminario de Historia Rural Andina, 2001.

Peralta, Víctor: La independencia y la cultura política peruana (1808-1821), Lima, Fundación M.J. Bustamante de la Fuente, IEP, 2010

Peset, Mariano: «Del censo consignativo a la hipoteca a finales del Antiguo Régimen», en De Dios, Salustiano et al. (coords.): Historia de la Propiedad, Crédito y Garantía, Madrid, Servicio de Estudios del Colegio de Registradores, 2007, 211-236. 
Ramos, Carlos: Historia del derecho civil peruano. Siglos XIX y XX. I. El orbe jurídico ilustrado y Manuel Lorenzo de Vidaurre y IV. Legislación, abogados y exégetas, Lima, PUCP, 2003.

Rieu-Millán, Marie Laure: Los diputados americanos en las Cortes de Cádiz, Madrid, CSIC, 1990.

Robledo, Ricardo: «El crédito de los privilegiados durante la crisis del Antiguo Régimen», en Yun, Bartolomé (ed.): Estudios sobre capitalismo agrario, crédito e industria en Castilla (siglos XIX y XX), Salamanca, Junta de Castilla y León, 1991, 237-266.

Sala i Vila, Núria: «Desamortización eclesiástica y proyectos liberales en el mundo andino desde la perspectiva peruana», en Bodinier, Bernard, Congost, Rosa, Luna, Pablo F. (eds.): De la Iglesia al Estado. Las desamortizaciones de bienes eclesiásticos en Francia, España y América Latina, Zaragoza, Prensas Universitarias de Zaragoza, 2009, 223-250.

Sala i Vila, Núria: «El Trienio Liberal en el Virreinato peruano: los ayuntamientos constitucionales de Arequipa, Cusco y Huamanga, 1820-1824», Revista de Indias, LXXI, 253, 2011, 693-728.

Salinas, M. ${ }^{a}$ del Carmen, Birrichaga, Diana y Escobar, Antonio (coords.): Poder y gobierno local en México, 1808-1857, Zinacantepec, El Colegio Mexiquense, Colegio de Michoacán, Universidad Autónoma de México, 2011.

Tello, Enric, «La fi del censal: reducción de l'interès o vaga de pensions? (17501861)», Bulletí de la Societat Catalana d'Estudis Històrics, XV, 2004, 125155.

Tello, Enric: «Crisis del Antiguo Régimen y crisis del sistema crediticio: el fin de los censos consignativos en España (1705-1885)», en Dios, Salustiano de et al. (coords.): Historia de la Propiedad, Crédito y Garantía, Madrid, Servicio de Estudios del Colegio de Registradores, 2007, 237-270.

Wobeser, Gisela von: «La consolidación de vales reales como factor determinante de la lucha de Independencia en México, 1804-1808», Historia mexicana, 56, 2, 2006, 373-425.

Yun, Bartolomé: «Transacción mercantil y formas de transmisión de la propiedad territorial», Hispania, LV/III, 1995, 846-885.

Zárate, Verónica: «El testamento político de los diputados americanos en 1814», Anuario de Estudios Americanos, 45, 1988, 343-382. 